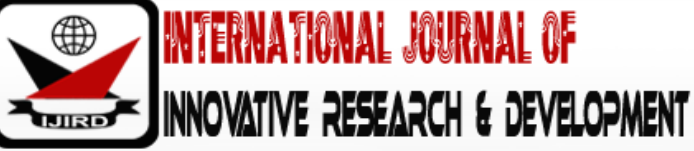

ISSN 2278 - 0211 (Online)

\section{Prevalence of Urinary Schistosomiasis, Knowledge, Attitude, Perception and Treatment Practices in Fikyu Community, USSA Local Government Area of Taraba State, North Eastern Nigeria}

\begin{tabular}{|c|}
\hline $\begin{array}{c}\text { DAWUDA, BM } \\
\text { Department of Biological Sciences, Federal University Wukari, Taraba State, Nigeria } \\
\text { BALA, AY } \\
\text { Associate Professor, Department of Biological Sciences, Usmanu Danfodiyo University } \\
\text { Sokoto, Sokoto State, Nigeria } \\
\text { AGBO, J0 } \\
\text { Department of Biological Sciences, Federal University Wukari, Taraba State, Nigeria } \\
\text { AGERE, IH } \\
\text { Professor, Department of Biological Sciences, Federal University Wukari, } \\
\text { Taraba State, Nigeria }\end{array}$ \\
\hline
\end{tabular}

\begin{abstract}
:
Schistosomiasis is one of the major parasitic diseases of man ranking second only to malaria in terms of its socio-economic and public health importance in tropical and subtropical areas. Study on Urinary Schistosomiasis was conducted to determine its prevalence and to assess the knowledge, attitude, perception and treatment practice among people in Fikyu community of Ussa LGA, Taraba State between February to October. Three hundred and ninety urine samples collected were screened visually for gross haematuria, using commercial reagent strip (Medi-test combi-9) in accordance with manufacturer's instruction for microhaematuria and proteinuria, filtration technique was used to detect presence of Schistosoma haematobium eggs in urineand then Questionnaire was also administered to subjects to collect information on socio-demographic data, knowledge, attitude, perception and treatment practices. An overall prevalence of $32.05 \%(125 / 390)$ was recorded out of the three hundred and ninety urine samples examined. Microhaematuria was detected in 209(53.59\%) while Proteinuria detected in 390(100\%) of the urine samples screened for both microhaematuria and proteinuria respectively. 351(90\%) respondents were knowledgeable of the snail in the area. All the respondents (100\%) believed that presence of blood in the urine is a sign of sickness. $58.70 \%$ subjects did nothing on the treatment of the infection, $40 \%$ went to hospital for treatment while $1.03 \%$ sought for traditional treatment for the infection. Findings from this study revealed that urinary schistosomiasis is present in the area and therefore urgent intervention in the study area is needed.
\end{abstract}

Keyw ords: Prevalence, urinary schistosomiasis, knowledge, Fikyu, USSA, Nigeria

\section{Introduction}

Schistosomiasis is a wide spread parasitic infection caused by blood flukes of the genus Schistosoma and transmitted by specific fresh water snails (Agi and Okafor, 2005). The disease, caused by trematode Schistosoma haematobium, is water based parasitic disease transmitted by fresh water-snails of the genus Bulinus (Ladan et al., 2012). Schistosomiasis is one of the major parasitic diseases of man ranking second only to malaria in terms of its socio-economic and public health importance in tropical and subtropical areas (Ogbe,2002).

It is one of the most widespread diseases in the world and is found in approximately 76 countries and territories located in Africa, South America, Middle East and the Asian southern continent (Engels et al, 2002). Over 207 million people in these countries are infected; of these, 120 million are symptomatic, with 20 million having severe clinical disease (Steinmann et al., 2006). Risk factors include persons living in or travelling to areas where schistosomiasis occurs, and those who come in contact with fresh water where the intermediate host is present (Houmsou et al.,2012). In sub-Sahara Africa, 192 million are estimated to be infected with the two forms of schistosomiasis (intestinal and urinary), and Nigeria 
recording the largest number of infections with about 29 million cases (Hotez and Kamath, 2009). Despite more than a century of highly effective antischistosomal drug, the eradication of the disease is still far from actualization (Bigwan et al., 2012). According to Ogbe (2002), the control of schistosomiasis in countries in sub-saharan Africa deserves renewed attention and commitment. Comprehensive mapping of the disease problem is lacking. Detailed identification of the problem areas is very pertinent. In addition, for control strategies in resource poor settings to be effective, there is need for rapid and accurate identification of disease, monitoring of population risks, adequate treatment and quantification of infection rates using limited economic and human resources (French et al., 2007). It is therefore important, that all possible data on epidemiological nature of urinary schistosomiasis and the current health education strategies are required for adequate assessment and intervention to address the persistence of urinary schistosomiasis infections. There are reports of urinary schistosomiasis in Bali Local Government Area of Taraba, where Monday et al., (2014) reported a prevalence of $15.5 \%$ and concluded that the area is endemic for urinary schistosomiasis. There is paucity of data on urinary schistosomiasis in Fikyu community of Ussa Local Government Area of Taraba State, because based on my knowledge there was no research work conducted in study area whose inhabitants are predominantly farmers, fishermen and civil servants and the people strongly rely on streams, rivers and wells for their daily water activities. The problem and concern are that data are not available therefore, the correct planning and preventive strategies to control the spread of urinary schistosomiasis are limited. This study was therefore undertaken in order to determine prevalence of infection and assess knowledge, perception and treatment practice among people of Fikyu community. These can be used to plan strategies for control program for the area in accordance with WHO recommendation.

\section{Materials and Method}

\subsection{The Study Area}

The research work was carried out in Fikyu Community of Ussa Local Government Area of Taraba State, located in North Eastern Nigeria. Ussa Local Government Area lies between (latitude $7011^{\prime \prime} \mathrm{N}$ and longitude $10^{\circ} \mathrm{02}$ " E), borders the Republic of Cameroon in the South; the Donga river form its Northern boundary, and it occupies an Area of about 1,495km per square, and has an estimated population of 105,070 persons (Ojo et al. 2013). Fikyu community is about seven kilometers $(7 \mathrm{~km})$ away from Lissam and twelve kilometers $(12 \mathrm{~km})$ away from Takum Local Government Area and is bounded in the north west by Ndekwe, on the south east by Nyazo, on the south west Yamsa Achilo and on the south by Kpambo Yashe. River Gamana runs through the southern part of the community at latitude $6058^{\prime \prime} \mathrm{N}$ and longitude $9032^{\prime \prime} \mathrm{E}$. The inhabitants are Kuteb ethnic origin and their major occupation includes farming, fishing, irrigation and few others that are civil servants. Its terrain is undulating and many major topographical features. There are however, some streams which flow across the Fikyu community down to River Gamana, these streams include Yangtxu, Usuun, Tgixtsi and Ukang (TSLS, 2003). Temperature is usually high throughout the year with no monthly average below $29^{\circ} \mathrm{C}$ annual and range of about $26^{\circ} \mathrm{C}$. The hottest period is between February to April, just before the rain sets in. Relative humidity is constantly high, except December to February when hamattan brings in dry and cold conditions. Most of the inhabitants keep visiting the river Gamana at least twice or more a day for various activities such as washing, bathing, swimming, fishing and irrigation (Ojo et al., 2013).

\subsection{Diagnostic Chemical Reagent Strip}

Urine samples collected from the six selected villages in Fikyu Community were examined for the presence of blood (microhaematuria) and protein (proteinuria) using strip of commercially prepared reagent strip (Medi Combi 9 Reagent strips) which was dipped into each of the urine samples collected and the colour change was match with standard colours by the side of the container of the reagent strips according to Olajumoke et al. (2014).

\subsection{Urine Filtration Technique}

For the detection of Schistosomahaematobium eggs and enumeration, the analysis of the urine samples for the presence of eggs was done using standard filtration technique as described by Pugh (1978). The method involved the use of vacuum-pump filtration machine (Millipore corporation Bedford, Massachusetts 01730 USA). A $5.5 \mathrm{~cm}$ Whatman's filter paper was inserted in the filtration unit. After shaking the urine sample, $10 \mathrm{ml}$ of it was withdrawn with the help of a stringe and injected into filtration unit. After filtration, the filter paper was carefully removed using a pair of forceps and placed on a clean sheet of paper and stained with a drop of lugol's iodine solution and a drop of ninhydrin solution to enhanced staining. The stained filter paper was allowed to dry for about 24 hours at room temperature for the eggs to pick up the stain, after which it was placed on a clean glass slide and observed systematically under the electric microscope at x10 and x40 magnification with the condenser Iris closed sufficiently to give good contrast.

\subsection{Analysis of Data \\ Frequency distribution tables, percentage prevalence of urinary schistosomiasis infections was estimated using standard formula.}

\section{Results}

\subsection{Prevalence of Urinary Schistosomiasis in the Study Area}

The results of the study showed that out of the 390 samples of urine examined for Schistosoma haematobium eggs, $125(32.05 \%)$ samples were found to be infected, a prevalence of $32.05 \%$. Results of visual observation of urine samples 
observed macroscopically for different colours of urine indicated that urine samples from $218(55.9 \%)$ subjects were observed to have light yellow colour (normal colour of urine), 169(43.3\%) light brown colour (low presence of microhaematuria and proteinuria), $3(0.83 \%)$ had presence of medium microhaematuria and proteinuria (dark brown colour), however none of the urine samples which were examined for different colours had bloody brown colour (Figure 3). The results of prevalence of urinary schistosomiasis revealed that the highest prevalence of infection (36.09\%) was observed among subjects whose urine colour were light brown, while the least prevalence of infection (29.36\%) was observed in those whose urine colour were light yellow (Table 1).

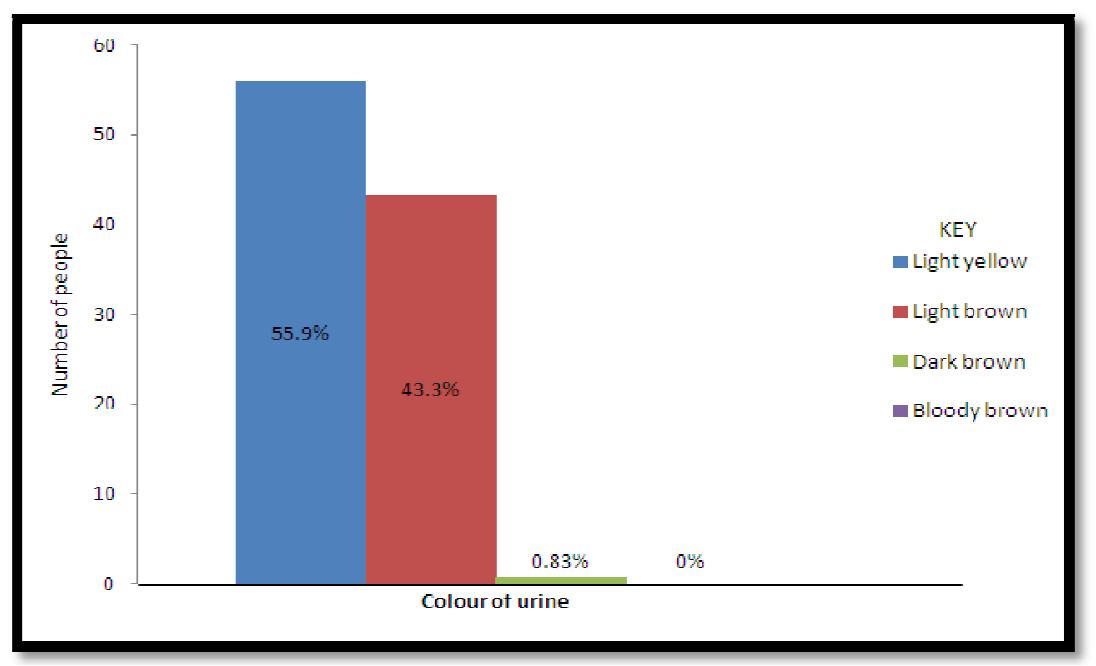

Figure 1: Distribution of Colour of Urine in the Study Area

- Light yellow, normal colour of urine.

- Light brown, low presence of proteinuria and microhaematuria.

- Dark brown, medium presence of proteinuria and microhaematuria.

- Bloody brown, visible presence of haematuria.

\begin{tabular}{|c|c|c|c|}
\hline Colour Of Urine & Number Examined & Number Positive & Prevalence (\%) \\
\hline Light yellow & 218 & 61 & 29.36 \\
\hline Light brown & 169 & 64 & 36.09 \\
\hline Dark brown & 3 & 0 & 0 \\
\hline Bloody brown & 0 & 0 & 0 \\
\hline Total & 390 & 125 & 32.05 \\
\hline
\end{tabular}

Table 1: Prevalence of Urinary Schistosomiasis with Respect to Colour of Urine in the Study Area

- Light yellow, normal colour of urine.

- Light brown, low presence of proteinuria and microhaematuria.

- Dark brown, medium presence of proteinuria and microhaematuria.

- Bloody brown, visible presence of haematuria.

3.2. Prevalence of Microhaematuria and Proteinuria among Inhabitants in Fikyu Community

Microhaematuria was detected in 209(53.59\%) in the urine samples screened while proteinuria was detected in 390(100\%) urine samples (Table 2). The most sensitive (100\%) Schistosoma morbidity indicator was proteinuria while microhaematuria was the least sensitive (54.4\%) indicator of infection (Table 3). However, microhaematuria which recorded lower value in sensitivity compared to proteinuria showed higher specificity of $47.5 \%$ (Table 4).

\begin{tabular}{|c|c|c|c|c|c|}
\hline $\begin{array}{c}\text { Name of } \\
\text { Villages }\end{array}$ & $\begin{array}{c}\text { Number } \\
\text { Examined }\end{array}$ & $\begin{array}{c}\text { Number } \\
\text { Positive }\end{array}$ & Prevalence (\%) & $\begin{array}{c}\text { Number } \\
\text { Positive }\end{array}$ & Prevalence (\%) \\
\hline Kabnyansum & 63 & 33 & 52.38 & 63 & 100 \\
\hline Kpakya & 69 & 28 & 40.58 & 69 & 100 \\
\hline Kabgbabaen & 57 & 33 & 57.89 & 57 & 100 \\
\hline Kabkinra & 63 & 31 & 49.21 & 63 & 100 \\
\hline Gafa & 70 & 39 & 55.71 & 70 & 100 \\
\hline Acha & 68 & 45 & 66.18 & 68 & 100 \\
\hline Total & 390 & 209 & 53.59 & 390 & 100 \\
\hline
\end{tabular}

Table 2: Microhaematuria and Proteinuria Related Prevalence of Urinary Schistosomiasis in the Study Area 


\section{Haematuria Proteinuria}

\section{Microscopy}

\begin{tabular}{|c|c|c|c|}
\hline Microhaematuria & +ve & -ve & Total \\
\hline + (Infected) & a (TP) 68 & b (FP) 139 & 207 \\
-(Not infected) & c (FN) 57 & d (TN) 126 & 183 \\
\hline Total & 125 & 265 & 390 \\
\hline
\end{tabular}

Table 3: Sensitivity and Specificity of Microhaematuria in the Diagnosi of Schistosoma Haematobium Infection among People of Fikyu Community

- TP: True positive, FP: False positive, FN: False negative, TN: True negative

- Sensitivity $=\mathrm{TP} /(\mathrm{TP}+\mathrm{FN}) \times 100=54.4 \%$

- $\quad$ Specificity $=\mathrm{TN} /(\mathrm{TN}+\mathrm{FP}) \times 100=47.5 \%$

- $\quad$ Positive predictive value (PPV) $=\mathrm{a} /(\mathrm{a}+\mathrm{b}) \times 100=32.85 \%$

- $\quad$ Negative predictive value $(\mathrm{NPV})=\mathrm{d} /(\mathrm{d}+\mathrm{c}) \mathrm{x} 100=68.85 \%$

\begin{tabular}{|c|c|c|c|}
\hline \multicolumn{4}{|c|}{ Microscopy } \\
\hline Proteinuria & +ve & -ve & Total \\
\hline${ }^{+}$(Infected) & a (TP) 125 & b (FP) 265 & 390 \\
\hline -(Not infected) & $\mathrm{C}(\mathrm{FN}) 0$ & $\mathrm{~d}(\mathrm{TN}) 0$ & 0 \\
\hline Total & 125 & 265 & 390 \\
\hline
\end{tabular}

Table 4: Sensitivity and Specificity of Proteinuria in the Diagnosis of Schistosoma Haematobium in the Study Area

- $\mathrm{TP}=$ True positive, $\mathrm{FP}=$ False positive, $\mathrm{FN}=$ False negative, $\mathrm{TN}=$ True negative

- Sensitivity $=\mathrm{TP} /(\mathrm{TP}+\mathrm{FN}) \times 100=100 \%$

- $\quad$ Specificity $=\mathrm{TN} /(\mathrm{TN}+\mathrm{FP}) \times 100=0 \%$

- Positive predictive value $(\mathrm{PPV})=\mathrm{a} /(\mathrm{a}+\mathrm{b}) \mathrm{x} 100=32.05 \%$

- Negative predictive value $(\mathrm{NPV})=\mathrm{d} /(\mathrm{d}+\mathrm{c}) \times 100=0 \%$

\section{Community Perception on Bloody Urine, Treatment Practices, Knowledge and Season of Snail in the Study Area}

Although all the respondents $390(100 \%)$ believed that presence of blood in urine is a sign of sickness (Figure 4), $229(58.70 \%)$ did nothing on the treatment of the infection, 157(40.00\%) went to hospital for treatment of the infection while only $4(1.03 \%)$ sought for traditional treatment for the infection (Figure 5). Results of the study also revealed that those who did nothing for the treatment recorded the highest prevalence of infection 79(34.50\%), followed by those that went to hospital for treatment $45(28.66 \%)$ while the least prevalence were observed among subjects that sought for traditional treatment $1(25.00 \%)$ (Table 5). The inhabitants whose seek for traditional treatment mentioned the name of plant used for the treatment as "Igkik" in Kuteb native language. Method of preparation is by boiling the roots of the plant to be administered two to three times per day for two weeks respectively. The inhabitants that seek for this treatment all considered the plant extract to be effective.

Result obtained on the knowledge of snail intermediate host indicated that, 351(90\%) respondents said "YES" they have knowledge about snail while 39(10\%) respondents are not knowledgeable about the snail (were on the side that said "NO") (Figure 6). Among the respondents that were knowledgeable of the snail, 114(91.2\%) respondents were observed to have urinary schistosomiasis infection while 237(89.4\%) respondents were not found infected with the infection. However, on the side that said "no" (did not have any knowledge on the snail), 11(8.8\%) subjects were found infected with urinary schistosomiasis and 28(10.6\%) subjects were observed negative for urinary schistosomiasis infection. Results revealed that all the inhabitants $390(100 \%)$ did not know that snail is a medium for transmission of urinary schistosomiasis infection, however $125(100 \%)$ respondents were observed to have the infection while 265(100\%) respondents were found negative for urinary schistosomiasis infection (Table 6).

The season of snail availability showed that (90.3\%) volunteers have seen snails during dry season, however no response on wet season while (9.7\%) subjects did not have any idea about the season of snail availability (Figure 7). 


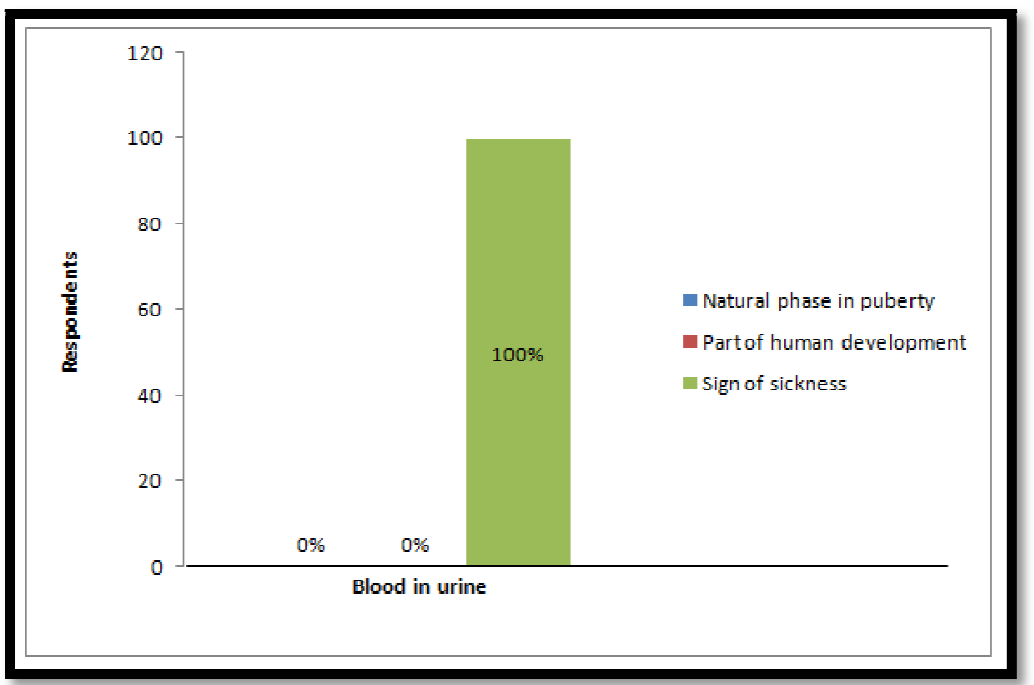

Figure 2: The Distribution of Respondents on Perception of Bloody Urine

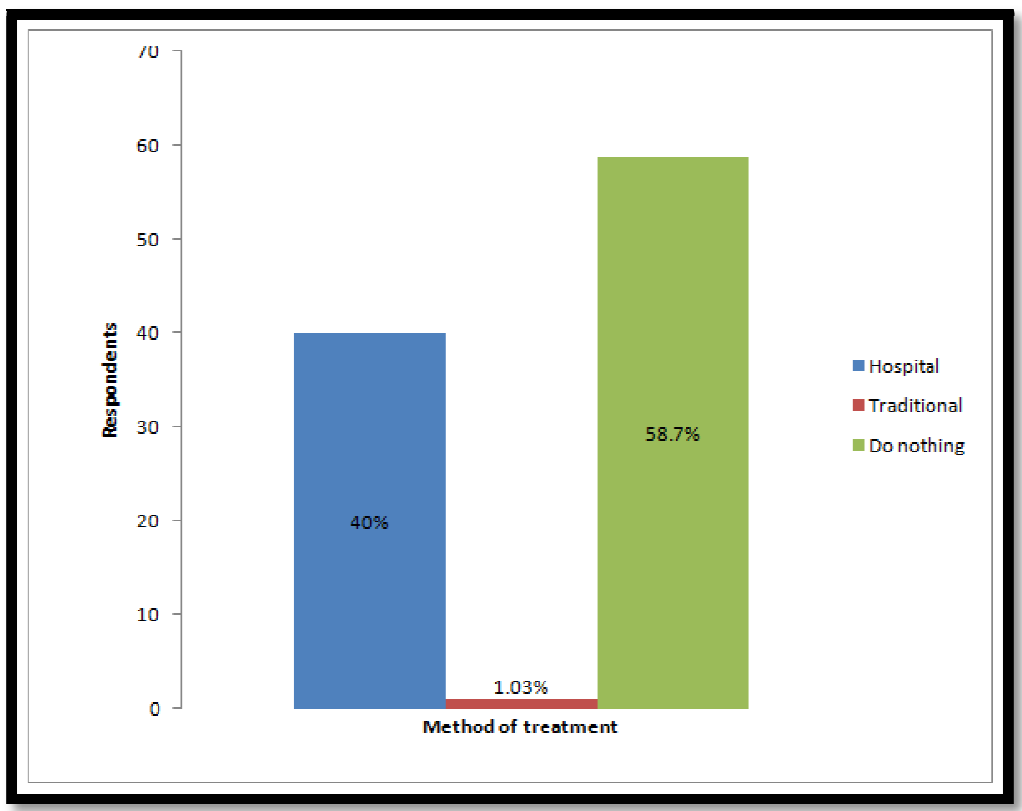

Figure 3: Treatment Seeking Practices of Urinary Schistosomiasis in the Study Area

\begin{tabular}{|c|c|c|c|}
\hline Treatment & Number Examined & Number Positive & Prevalence (\%) \\
\hline Hospital & 157 & 45 & 28.66 \\
\hline Traditional & 4 & 1 & 25.00 \\
\hline Do nothing & 229 & 79 & 34.50 \\
\hline Total & 390 & 125 & 32.05 \\
\hline
\end{tabular}

Table 5: Prevalence of Urinary Schistosomiasis in Relation to Treatment Practice in the Study Area

\begin{tabular}{|c|c|c|c|c|}
\hline Observation & Response & Number of Respondents & Positive (\%) & Negative (\%) \\
\hline Knowledge on Snail & Yes & 351 & $114(91.2 \%)$ & $237(89.4 \%)$ \\
& No & 39 & $11(8.8 \%)$ & $28(10.6 \%)$ \\
\hline $\begin{array}{c}\text { Snail as a Medium for } \\
\text { Transmission }\end{array}$ & Yes & 0 & $0(0 \%)$ & $0(0 \%)$ \\
& No & 390 & $125(100 \%)$ & $265(100 \%)$ \\
\hline
\end{tabular}

Table 6: Prevalence of Urinary Schistosomiasis with Respect to Knowledge on Snail as Medium in Transmission of Schistosomiasis 


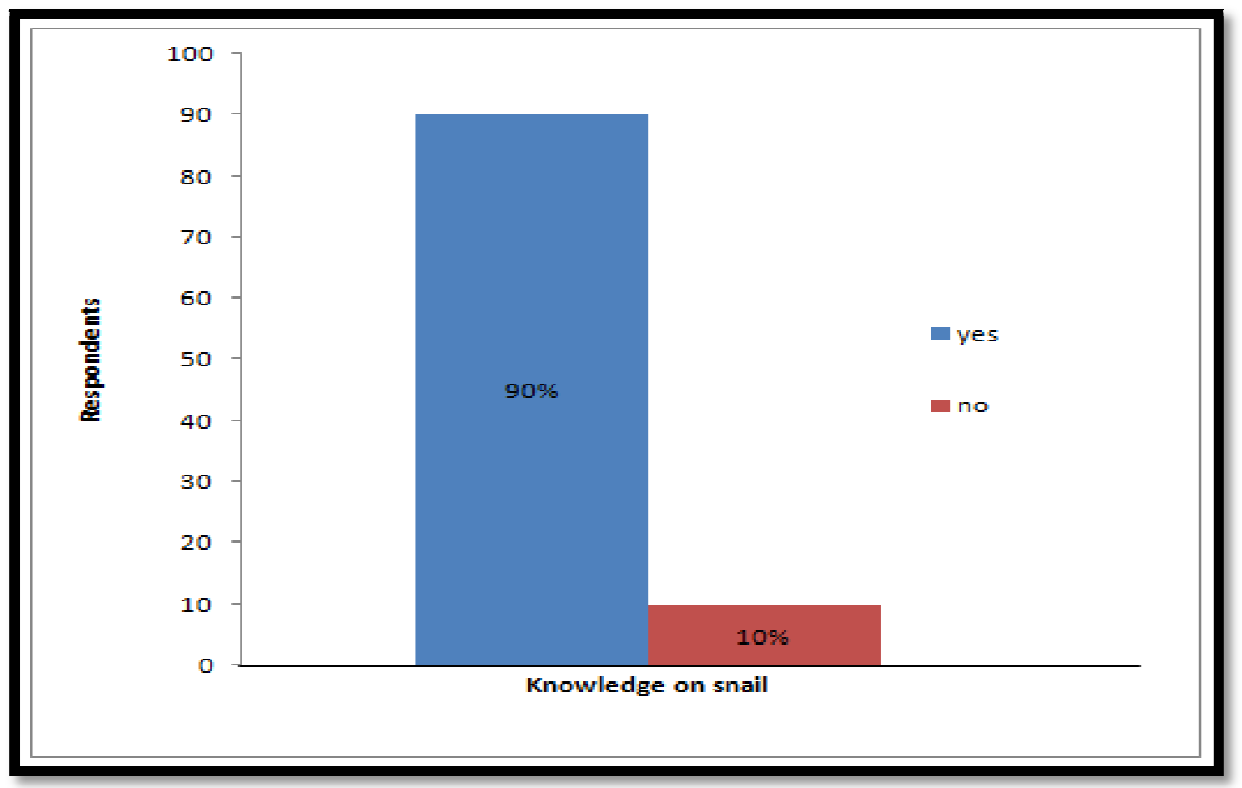

Figure 4: Knowledge on Snail as Medium of Transmission of Schistosomiasis

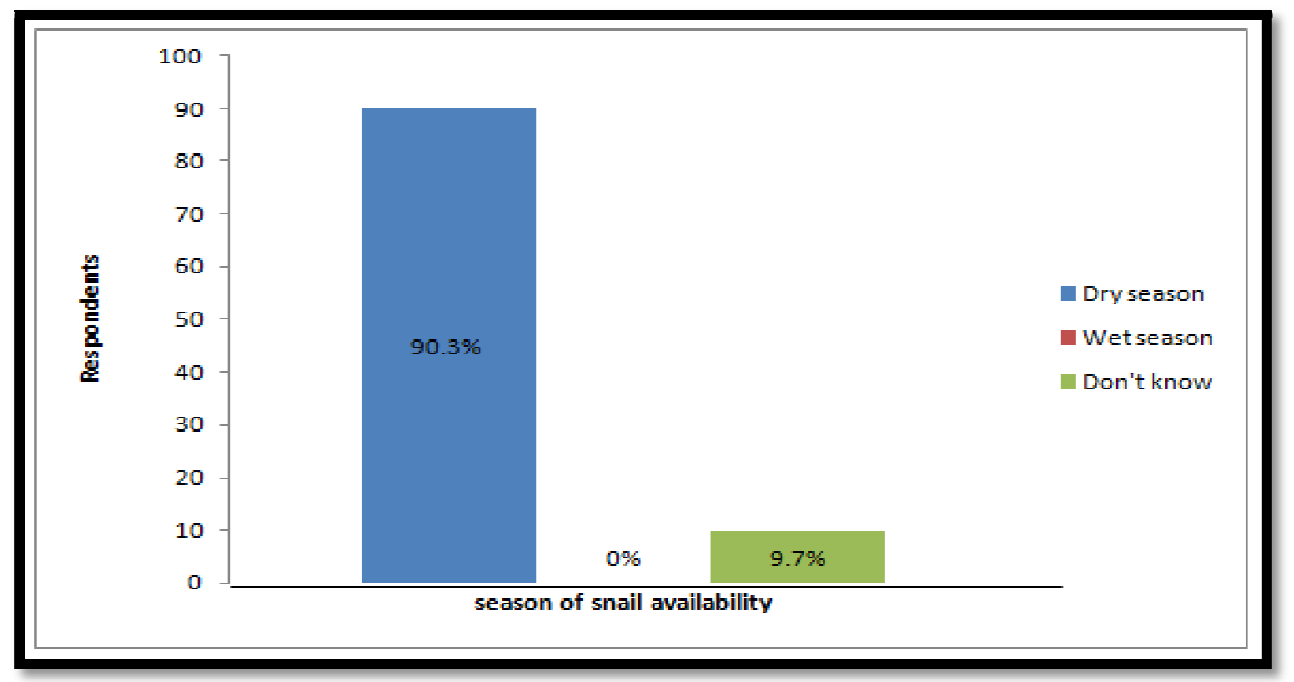

Figure 5: The Distribution of Respondents on Season of Snail Availability in the Study Area

\section{Discussion}

The overall prevalence (32.05\%) obtained in the present study seem to be higher than what was reported in some parts of Taraba State and other parts of Nigeria by earlier reseachers. Agere et al. (2010) reported a prevalence of 28.8\% in Jalingo and Ardokola Local Government Areas, while Monday et al. (2014) observed a prevalence of 15.5\% in Bali town, Bali Local Government Area, Taraba State and others were, Ejima and Odaibo (2010) who reported 18.7\% in the NigerBenue basin of Kogi State; 10.0\% prevalence reported by Bigwan et al. (2012) in Potiskum metropolis, Yobe State; Rine et al. (2013) observed 16.3\% in Lafia Nasarawa State; Iwu et al. (2015) reported 9.2\% prevalence of infection in Umukabia community of Ehime Mbano Local Government Area of Imo State. However, the prevalence rate observed in this present study seem to be lower than what was observed in other areas, $41.5 \%$ prevalence rate observed by Houmsou et al. (2012) in two Local Government areas (Buruku and Katsina -Ala) of Benue State, Okon et al. (2008) reported prevalence of 45.3\% in a community in South Eastern Nigeria, 48.2\% prevalence reported by Babatunde et al. (2013) in two peri-urban communities in South western Nigeria, Nmorsi et al. (2005) reported 65.0\% prevalence in Ikpeshi, a rural community of Edo State and 74\% prevalence of infection reported by Bala et al. (2012) in Abarma village of Gusua Zamfara State. The presence of urinary schistosomiasis in this present study reflects the higher level of exposure and dependence of the inhabitants of Fikyu community on the infested water bodies like river and stream, these water bodies are the sources of water supply for all their recreational and domestic needs.

Based on the result obtained from the respondents in the study area on their perception about presence of blood in urine all the respondents believed that presence of blood in persons urine is not normal "it is a sign of sickness".

Treatment practice among the respondents in the study area toward urinary schistosomiasis infection revealed 58.7\% of the respondents do not seek treatment for the signs and symptoms of urinary schistosomiasis infection, thus they were recorded with high prevalence rate of $34.50 \%$ than the others $40 \%$ respondents whose seek for treatment in nearby clinics and hospitals had prevalence rate of $28.66 \%$, however $1.03 \%$ respondents rely on traditional treatment were recorded least prevalence rate of $25.0 \%$. 
About ninety percent (90\%) of the respondents were able to identify with the snail and $10 \%$ were unknowledgeable about the snail, they have never seen the snail before now. None of the respondents in study area had any ideas on transmission of urinary schistosomiasis infection through the snail intermediate host.

Most of the participants recognized dry season as a season which snails are commonly available but have no idea how the infected snails infest water bodies with cercariae. And few other respondents don't know about the season of snail availability in the Area.

\section{Conclusion}

The present research found a moderate prevalence of urinary schistosomiasis in Fikyu community of Ussa Local Government Area, Taraba State. Majority of the respondents in the study area do not seek treatment for signs and symptoms of the infection but others few of the respondents seek for treatment in hospital and on traditional treatment. Respondents believed that presence of blood in urine is a sign of sickness. Ninety percent respondents have knowledge of snail in the area but all the subjects have no idea on the transmission of urinary schistosomiasis through snail. Most of the participants recognized dry season as a season which snails are available. Therefore, there is need for Ussa Local Government Chairman and Taraba State Government to educate the inhabitants of Fikyu community on urinary schistosomiasis and other related diseases and to mount successful control interventions in this area.

\section{References}

i. $\quad$ Agere, I. J., Istifanus, W. A., and Kela, S. L. (2010). Water usage and transmission of schistosoma haematobium in Jalingo and Ardo-kola Local Government Area of Taraba State, Nigeria. Nigerian Journal of Sciences, Technology and Environmental Education, 3(1): 87-95.

ii. Agi, P. I. and Okafor, E. J. (2005). The epidemiology of Schistosoma haematobium in Odau community in the Niger Delta Area, Nigerian journal of applied Science and environment Management, 9(3):37-43.

iii. Babatunde, T. A., Asaolu, S. O. and Sowemimo, O. A. (2013). Urinary schistosomiasis among pre-school and school aged children in two peri-urban communities in south-west Nigeria. Journal of Parasitology and vector Biology. Vol. 5(7), PP. 96-101

iv. Bala, A. Y., Ladan, M. U. and Mainasara, M. (2012). Prevalence and intensity of urinary schistosomiasis in Abarma village, Gusau, Nigeria. Science World Journal,7(2)1-4

v. Bigwan, E. I., Tinja, B.and Damen, J. G. (2012). Prevalence of Schistosomiasis among Secondary School Boarding Students in Potiskum metropolis, Yobe State, North-eastern Nigeria. Bayero Journal of Pure and Applied Science, 5(1): 155-158.

vi. Engels, D., Chitsulo, L., Montresor, A. and Savioli, L. (2002). The global epidemiology situation of schistosomiasis and new approaches to control and research. Acta Tropica82:139-146.

vii. Ejima, I. A. A. and Odaibo, A. B. (2010). Urinary schistosomiasis in Niger-Benue basin of Kogi State, Nigeria. International Journal of Tropical Medicine, 5:73-80

viii. $\quad$ French, M. D., Rollinson, D., Basanez, M. G., Mgeni, A. F., Khamis, I. S., Stothard, J. R. (2007). School-based control of urinary schistosomiasis on Zanzihar, Tanzania: monitoring micro-haematuria with reagent strips as a rapid urological assessment. Journal of Pediatric Urology, 3(5):364-8.

ix. Hotez, P. J. and Kamath, A. (2009). Neglected tropical diseases in sub-saharan Africa: review of Their prevalence, distribution, and disease burden. Plos Neglected Tropical Diseases,3, 412- 420.

x. Houmsou, R. S., Amuta, E. U. and Sar, T. T. (2012). Profile of an epidemiological study of urinary schistosomiasis in two Local Government Areas of Benue State, Nigeria. International Journal of Biomedicine,1(1): 39-48.

xi. Iwu, R. U., Azoro, A. V. and Onuha, J. N. (2015). Urinary schistosomiasis: water contact frequency and infectivity among school aged pupil/students in Umukabia community of Ehime Mbano Local Government Area of Imo State, Nigeria. Journal of parasitology and vector Biology. Vol. 7(3) 53-57

xii. $\quad$ Ladan, M. U.; Abubakar, U.; Abdullahi, K., Bunza, M. D. A.., Ladan, M. J. and Adamu, T. (2012). Studies on urinary schistosomiasis in selected villages around Gusua Dam site, Zamfara State, Nigeria. Nigerian Journal of Basic and applied Science. 20(3):189-194.

xiii. Monday, I. E., Francis J. I., Lamidi, B. T., Mohammad, S. U. (2014). Investigating urinary Schistosomiasis in Bali town, Bali Local Government Area, Taraba State, Nigeria. African Journal of parasitology. Vol 35, No. 1 and 2.

xiv. Nmorsi, O. P. G., Egwunyenga, O. A., Ukwandu, N. C. D. and Nwonkolo, N. Q. (2005). Urinary schistosomiasis in a rural community in Edo State, Nigeria. Esinophiluria as a diagnostic marker. African Journal of Biotechnology, 4:183-189.

xv. Ogbe, M. G. (2002). Schistosomiasis (Bilharziasis); An ancient water borne disease that occurs in some of our communities. The zoologist1(2): $91-104$.

xvi. Ojo C. O., Nuhu H. S. and Igbankwe T. A. (2013). Gender analysis of rural dwellers accessibility to free natural resources in Ussa Local Government Area of Taraba State, Nigeria. Asian Journal of Agriculture and rural development, 3(9):609-614.

xvii. Okon, O., Ememayom, A. and Opara, K. (2008). Reliability of self- reported blood in urine for diagnosis of schistosoma haematobium in a community in South Eastern Nigeria, The Journal of Epidemiology, vol 7(2)86-91

xviii. Olajumoke, M.; Sunday A., Ayodele, J.; Roseangela, N. and Claire, O. (2014). A cross-sectional study on urogenital schistosomiasis in children; haematuria and proteinuria as diagnostic indicators in an endemic rural area of Nigeria.African Health Sciences;14(2):390-396 
xix. $\quad$ Pugh, R. N. H. (1978). Malumfashi endemic disease research project II. Ann. Tropical Medicine and Parasitology.73: 295.

xx. Rine, C. R., Habibu, T. and Jasini, A. M. (2013). Epidemiology of urinary schistosomiasis among secondary school students in Lafia, Nasarawa State, Nigeria. Journal of Biology, Agriculture and Health care. Vol.3 No. 2

xxi. Steinmann, P., Keiser, J., Bos, R., Tanner, M. and Utzinger, J. (2006). Schistosomiasis and water Resources Development; Systematic Review, Meta -analysis, and Estimates of People at risk. Lancet infectious Diseases,6: 411-425. 